\title{
Duas palavras acerca da epígrafe de Turguêniev à novela Noites brancas, de Dostoiévski"
}

\author{
Boris N. Tikhomírov ${ }^{1}$
}

\begin{abstract}
Resumo: Este artigo tem como objetivo desvendar a função da epígrafe da novela Noites brancas (1848), de F. M. Dostoiévski, composta pelos três versos finais do poema "Flor" (1843), de I. S. Turguêniev. A função da epígrafe é analisada em dois planos: no explícito, tradicional, e num plano oculto, que revela seu significado apenas aos iniciados. No primeiro plano, a epígrafe de três versos, tomada isoladamente do texto-fonte de Turguêniev, focaliza a ideia do autor de Noites brancas dotando-se de um conteúdo específico no contexto da novela de Dostoiévski. No segundo plano, junto à reconstrução do contexto completo do poema "Flor", nos mesmos versos poéticos revela-se de modo significativo um outro conteúdo, a princípio oposto à ênfase do autor de Noites brancas. Em suma, a epígrafe revela-se como polemicamente "fendida", nela cruzam-se posições ideológicas e estéticas diametralmente opostas. Como destinatário da controversa, que é mantida no plano oculto do funcionamento da epígrafe, aparece I. S. Turguêniev, com quem, na década de 1840, Dostoiévski mantivera relações complexas de amizade e inimizade.
\end{abstract}

Palavras-chave: Dostoiévski; Turguêniev; Noites brancas; epígrafe.

Аннотация: Статья посвящена раскрытию функций эпиграфа к повести Ф. М. Достоевского «Белые ночи» (1848) - трех финальных строк из стихотворения И. С. Тургенева «Цветок» (1843). Роль эпиграфа анализируется в двух планах — явном, традиционном и скрытом, раскрывающем свое значение только для посвященных. В первом плане трехстрочный эпиграф, взятый изолированно от тургеневского претекста, фокусирует авторскую идею «Белых ночей», наполняясь специфическим содержанием в контексте повести Достоевского. Во втором плане, при восстановлении полного контекста стихотворения «Цветок», в тех же стихотворных строчках обнаруживается существенно иное содержание, принципиально противоположное авторскому пафосу «Белых ночей». В итоге эпиграф раскрывается как полемически «расщепленный», внутри которого скрестились диаметрально противоположные идеологически и эстетические позиции. Адресатом полемики, содержащейся в скрытом плане функционирования эпиграфа, является И. С. Тургенев, с которым в 1840-е годы Достоевского связывали сложные

* $\quad$ Esse estudo foi realizado com apoio financeiro de RGHF (Rossiiskii Gumanitarnii Nautchnii Fond- Fundação de Ciências Humanas da Rússia), no âmbito do projeto de pesquisa científica "Por que e como liam as obras clássicas russas? (Do círculo de leitura à estratégia da carta)", 2015, n 15-34$11047 \mathrm{a}(\mathrm{ts})$. (N. A.)

1 Crítico literário, Doutor em Ciências da Filosofia, diretor adjunto de trabalhos científicos do Museu Memorial F. M. Dostoiévski, em São Petersburgo, Rússia. É autor de: - Lazar! Griadi von. Roman F. M. Dostoiévskogo Prestuplenie i Nakazanie v sovremennom protchteni: Kniga-kommentari. São Petersburgo: Serebriani viek, 2005. - Ia zanimaius etoi tainoi, ibo khotchu bit tcheloviekom: Stati $i$ esse o Dostoiévskom. São Petersburgo: Serebriani viek, 2012. - Dostoiévski na Kuznetchnom: Dati. Sobitia. Liudi. São Petersburgo: Kuznetchni pereulok, 2012. Contato: btikhomirov@ rambler.ru. (N. A.) 
отношения дружбы - вражды.

Ключевые слова: Достоевский; Тургенев; Белье ночи; эпиграф.

De início quero lembrar a epígrafe de Noites brancas, novela de Dostoiévski de 1848: “[...] fora ela criada/ Para ficar um instante/ Nas imediações do teu coração?... I. Turguêniev" (DOSTOIÉVSKI, 2005, 9)². Esses são os versos finais do poema "Flor", composto por Turguêniev, ainda no início de sua carreira literária, para o $\mathrm{n}^{\mathrm{o}} 8$ da revista Anais da Pátria, de 1843, cinco anos antes de Noites brancas. Desde já, adianto que "Flor" não foi publicado com o nome completo do poeta, mas assinado pelo pseudônimo “T. L.” (TURGUÊNEV, 1843, 296) - Turguêniev-Lutovinov. Dostoiévski poderia ter identificado o nome do autor através do próprio Turguêniev, quando das relações de amizade que com ele tivera nos anos de 1845-1846, ou, talvez, através de V. G. Bielínski, ou então de A. A. Kraiévski, editor de Anais da Pátria. Parece-me que revelar o pseudônimo de Turguêniev na epígrafe a Noites brancas foi-lhe, em princípio, essencial. A assinatura "T. L.” (como na publicação da revista) sob a parte superior das mesmas linhas não permitiria a Dostoiévski pôr em prática a parte "submersa" especial de sua ideia, realizada por meio da epígrafe. E se o escritor não soubesse que "Flor" era um poema de Turguêniev, acredito ser pouco provável que fizesse uso de todos os seus três últimos versos em sua obra Noites brancas.

No entanto, antes de iniciar uma conversa acerca da função oculta da epígrafe de Turguêniev à novela Noites brancas, de Dostoiévski, é necessário falar, ainda que resumidamente, acerca de sua função explícita, tanto mais que as funções oculta e explícita estão indissociavelmente ligadas.

A epígrafe de um romance, novela, poema etc., em seus devidos fins, é empregada com o objetivo de destacar o conceito artístico do autor, a ideia geral do escritor. Por um lado, ela antecipa a percepção do leitor, por outro, revela seu verdadeiro significado somente no final da leitura, conforme "incida" nela todo o conteúdo da obra. A novela Noites brancas ilustra bem essa definição.

Qual é a forma geral da concepção artística de Noites brancas? Infelizmente,

2 Para a tradução da epígrafe, houve uma adaptação da tradução de Nivaldo dos Santos. Com relação a outros trechos de Noites brancas, a reprodução foi literal. Os trechos que aparecerem em negrito são grifos do autor do artigo, os que aparecerem em itálico são de autoria do escritor. (N. T.) 
essa obra do início da carreira de Dostoiévski, apesar de toda a sua popularidade, foi pouco estudada por nós. Com relação à sua problemática, a imagem do herói principal o Sonhador -, existe uma imensa variedade de opiniões no que se refere à essência da posição do autor sobre ela. Na era soviética prevaleceu a concepção de V. I. Kirpotin. Ao absolutizar a proximidade de determinados aspectos de Noites brancas com o folhetim Crônica de São Petersburgo, de 1847, e abstrair daí que, em um caso, o sonhador por princípio é retratado por fora, a partir de uma posição objetiva do autor, e, em outro, temos diante de nós uma narrativa de confissão do próprio herói, Kirpotin descobriu em Noites brancas um julgamento do herói sonhador, uma "sentença de morte" do autor ao devaneio. No final da obra, o pesquisador constatou o "fracasso vital" do Sonhador, que não soube "lutar pela sua felicidade" (KIRPOTIN, 1978, 9698).

$\mathrm{Na}$ emigração russa, praticamente ao mesmo tempo que Kirpotin, K. V. Motchúlski propôs uma outra leitura de Noites brancas. Ao destacar no herói sonhador uma fonte autobiográfica, ele defende que nessa novela "Dostoiévski, sob o pretexto do devaneio, descreve a sua imaginação criativa acerca de literatura e história" (MOTCHÚLSKI, 1995, 264). Embora o pesquisador assinale que a "apreciação moral" do devaneio em Noites brancas "esteja fendida", para ele o mais importante é que o escritor "salienta [...] o imenso valor estético" do mundo dos sonhos em que o herói permanece. Ele escreve que "nunca antes o tema do devaneio havia sido apresentado em tão mágico esplendor poético" (MOTCHÚLSKI, 1995, 264). É muito importante o fato de Motchúlski ver como tema da novela a "transformação" do sonhador, que se realiza na história da relação entre o herói e Nástienka.

Nos anos seguintes, G. K. Chênnikov e I. V. Mann, entre outros, fizeram uma série de observações e correções importantes nas colocações de seus antecessores. Mas é necessário afirmar que ainda não há uma interpretação integral de Noites brancas que corresponda ao nível científico contemporâneo. Certamente, num artigo que se dedica a uma questão especial e particular, eu posso referir-me a questões conceptuais gerais apenas de forma seletiva, naquelas áreas que se mostram importantes para o objetivo da minha exposição.

Antes de tudo, é importante frisar que a imagem do Sonhador em Noites brancas não aparece de forma estática na novela, mas é apresentada dentro de uma dinâmica; é 
preciso abordar não apenas a "transformação" do herói na história, como faz Motchúlski, mas também levar em consideração o seu passado, como ele fora mencionado pelo Sonhador em seu monólogo confessional, enfim algumas fases de seu desenvolvimento moral e psicológico. Quando os pesquisadores apontam que o tema do devaneio apresenta-se em Noites brancas em um "esplendor poético mágico", mencionam características do tipo: "[...] ele é o próprio artista de sua vida e a cria a cada momento segundo um novo arbítrio" (DOSTOIÉVSKI, 2005, 39), recordam o comentário do herói acerca da "deusa fantasia" (DOSTOIÉVSKI, 2005, 34) etc., ou muitas vezes não se dão conta de que, para o tempo da ação no enredo, tal situação do Sonhador já está irremediavelmente perdida para ele, que essa fase de sua vida ficou no passado (é por isso, aliás, que ele descreve tudo para Nástienka "na terceira pessoa", olhando para si como que de fora). No momento do encontro com a jovem, já havia cerca de um ano que o herói passava por uma grave crise de devaneio. Nessa fase, é característica nele uma reflexão dolorosa acerca de seu mundo de sonhos; ele fala à heroína sobre o "pensamento negro que agora se apegou” (DOSTOIÉVSKI, 2005, 43) a ele. Revela-se nele um anseio de realidade, parece-lhe que, devido à sua fuga para o mundo dos sonhos, nele "enfraqueceu-se o talento para a vida real", que ele havia perdido "todo o tato, toda noção do autêntico" e que nunca seria "capaz de começar a viver uma vida autêntica" (DOSTOIÉVSKI, 2005, 42).

Não apenas o autor como o próprio herói de Noites brancas julga-se aqui com severidade. Mas já nos dois primeiros encontros com Nástienka ele diz à jovem tais palavras: "Dois minutos, e a senhorita me fez feliz para sempre. Sim, feliz! Sei lá, talvez a senhorita me tenha reconciliado comigo mesmo, tenha dissipado as minhas dúvidas..." (DOSTOIÉVSKI, 2005, 24). E novamente:

A senhorita sabe que me reconciliou por muito tempo comigo mesmo? Sabe que agora já não penso tão mal de mim mesmo como pensava em certos momentos? Sabe que, talvez, eu já não vá mais sofrer por ter cometido um crime e um pecado, pois uma vida assim é um crime e um pecado? (DOSTOIÉVSKI, 2005, 42).

Em sua confissão a Nástienka, em que o sonhador aparece como um homem que se encontra numa discórdia feroz consigo mesmo, esse reconhecimento soa bastante 
inesperado e requer comentário.

O seu sentido, obviamente, está no fato de que na história da relação do sonhador com Nástienka, quando não em devaneios, mas na realidade, ele soube manifestar magnanimidade, compaixão fraterna e afeto pela jovem infeliz, vem à tona que, "talento para a vida real", , na verdade, ele tem em alto grau. Esses encontros "se tornaram divisores em sua vida - escreve G. K. Chênnikov -, já que são justamente eles a revelar o maior dom do herói, do Sonhador: o dom de amar, de se condoer, de sentir compaixão, de ajudar altruisticamente" (CHÊNNIKOV, 2005, 82). Além disso, de acordo com o estudioso, essas qualidades do herói de Noites brancas de maneira alguma surgem com alguma "autonomia", com total independência de seu devaneio. Ao contrário, elas amadureceram e se formam em seu seio, foram estimuladas pela permanência "diária (do herói - destaque meu) na esfera do sublime" (CHÊNNIKOV, 2005, 82).

Sim, o Sonhador terá plena consciência de que o mundo de seus sonhos é uma "mistura de algo puramente fantástico, calidamente ideal e, ao mesmo tempo, [...] palidamente prosaico e comum [...]” (DOSTOIÉVSKI, 2005, 30). O isolamento hermético exclusivamente na esfera de seu mundo interior está prenhe de transformação do calidamente ideal para o "palidamente prosaico", "para não dizer: vulgar até o inverossímil" (DOSTOIÉVSKI, 2005, 30). Até a colisão com a vida real, o sonhador não podia saber com certeza como os seus sonhos sublimes se manifestariam e que forma tomariam na realidade. Daí suas dúvidas e temores. E o herói de Noites brancas é infinitivamente grato a Nástienka justamente, talvez, pelo fato de ela lhe ter possibilitado, pela primeira vez, expressar na vida real as qualidades formadas e idealizadas em seus sonhos. Essa tomada de consciência resultou no reconhecimento paradoxal do Sonhador de que, após o encontro com Nástienka, uma jovem real, ele está pronto para se reconciliar com seus devaneios. Portanto, é com justiça, mas não de modo completamente satisfatório, que ele diz que "o encontro com Nástienka o salva do 'pecado' do devaneio" (MOTCHÚLSKI, 1995, 264). É verdade, mas o encontro com a jovem e a participação fraternal que ele tem no destino dela, ao mesmo tempo revelam e libertam aquele potencial "calidamente ideal" que, na solidão e no isolamento de "nossa

3 Expressão dedicada ao tema do sonhador no folhetim Crônica de São Petersburgo de 15 de junho de 1847. (N. A.) 
época séria, serí́ssima" (DOSTOIÉVSKI, 2005, 30), fora acumulado pelo devaneio do herói.

Claro que essa é apenas uma interpretação simplória de um dos aspectos mais importantes do conteúdo de Noites brancas. No terceiro e no quarto encontro com Nástienka, a tendência assinalada da figura do Sonhador no desenvolvimento do enredo psicológico-moral da novela será agravado de forma colossal. Mas o objetivo principal do artigo não me permite debruçar-me sobre isso, e passarei direto ao final da novela - à carta de despedida da heroína endereçada ao Sonhador e sua reação a ela, que nos levam de volta ao problema da epígrafe.

Talvez a particularidade mais surpreendente da função da epígrafe de Turguêniev em Noites brancas ("[...] fora ela criada/ Para ficar um instante/ Nas imediações do teu coração?...”) consista no fato de trazer à toa uma grave dificuldade à análise: ela deve ser relacionada com o papel do Sonhador no destino de Nástienka ou, ao contrário, com o papel dela no destino dele? Pesquisadores diversos apresentam respostas diferentes a essa questão. E o texto do último capítulo, "Manhã", fornece bases sólidas tanto para uma quanto para outra interpretação.

Com frequência, devido à epígrafe, são destacadas as palavras finais do Sonhador direcionadas a Nástienka - o último acorde na "construção musical" de Noites brancas, que, pela referência de Motchúlski, acrescenta à novela como um todo uma sonoridade "melancólica e iluminada": "Que seja claro o seu céu, que seja luminoso e sereno o seu lindo sorriso; abençoada seja você pelo momento de júbilo e felicidade que concedeu a um coração solitário e agradecido!/ Meu deus! Um momento inteiro de júbilo! Não será isto o bastante para uma vida inteira?...” (DOSTOIÉVSKI, 2005, 82).

Aqui se fala claramente acerca do "coração solitário e agradecido" do Sonhador e do "momento de júbilo" que Nástienka lhe concedeu. A projeção dessas linhas na epígrafe indica uma primeira interpretação. No entanto, não menos significativas para a interpretação da epígrafe são as palavras da carta de despedida da heroína: “Agradeço! Sim! Agradeço-lhe por esse amor. [...] vou recordar eternamente daquele instante em que o senhor abriu-me de maneira tão fraterna o seu coração e tão generosamente tomou o meu, mortificado, para guardá-lo, cuidar dele, curá-lo...” (DOSTOIÉVSKI, 2005, 80). Aqui revela-se um quadro mais complexo: como nas palavras finais do Sonhador, 
Nástienka menciona o coração dele, que generosamente tomou o dela ... Mas a ênfase maior é dada não a isso: o coração dele, "que se abre de maneira fraterna" para ela, não que recebe, mas que (ênfase semântica diferente!) tão generosamente toma o mortificado seu coração, "para guardá-lo, cuidar dele, curá-lo". E ela, por gratidão, promete "recordar eternamente" aquele "instante" tão significativo para o seu coração.

Essas linhas já não permitem simplesmente a possibilidade de um "movimento de roque" ${ }^{4}$ em relação às leituras precedentes, mas dão base para se dizer que na epígrafe acentua-se o significado mútuo da participação fraternal dos heróis de Noites brancas no destino um do outro - de um lado, a influência cicatrizante do Sonhador na angústia das dúvidas em que reside o "coração mortificado" da heroína; de outro, a salutar influência de Nástienka no coração atormentado do herói, que perdera "o talento para a vida real".

A essência desse lado do enredo psicológico e moral de Noites brancas, que encontra expressão nas palavras de Nástienka sobre o seu "coração mortificado" (não o que ama, que sente uma compaixão fraterna, etc., mas, justamente, o mortificado), tomado de presente pelo coração do Sonhador, tem de ser compreendida no sentido de que, ao corresponder ao seu apelo e confiar-lhe a sua infelicidade, a heroína também permitiu que se revelasse ao máximo o potencial moral da alma do Sonhador - o sentimento de compaixão, de autossacrifício, de altruísmo; em outras palavras, que se manifestasse plenamente o "talento para a vida real" que existe nele, e isso, como assinalei anteriormente, resultou na salvação do herói, que passava por uma crise intensa em seu devaneio. Parece que aqui já se forma a futura concepção religiosa e moral do Dostoiévski posterior, segundo a qual uma pessoa alcança o máximo de seu desenvolvimento por meio do sacrifício a serviço do outro, de todos.

E as palavras da epígrafe “... Fora ela criada /para [...]?” (com um ponto de interrogação, em contraste com o texto original de Turguêniev) elevam essa participação fraternal recíproca do Sonhador e de Nástienka no destino um do outro até a conjectura do autor de Noites brancas de que, de alguma forma, é exatamente nisso que consiste o propósito do homem na Terra, e de que a realização - ainda que por um "instante" desse propósito eterno dá sentido a toda a existência humana.

Desse modo, a epígrafe de três linhas de Noites brancas não apenas está em 
perfeita consonância com o conteúdo da obra como evidencia e reforça a essência da concepção artística de Dostoiévski.

No entanto, tal efeito mantém-se apenas até o momento em que examinamos as linhas do poema de Turguêniev isoladamente, sem relacioná-la com o contexto poético do qual Dostoiévski as retira. Agora chegou o momento de reconstituir esse contexto e analisar o sentido autêntico que o autor (Turguêniev) deu a essas linhas examinadas. Eis, então, o poema completo "Flor":

Já lhe ocorreu de, num bosque sombrio,

$\mathrm{Na}$ relva jovem e primaveril

Encontrar uma flor simples e modesta?

(Tu estavas sozinho numa estranha terra)

Ela te aguardava na relva orvalhada

Ela cresceu só...E para ti seu perfume puro

Seu primeiro perfume ela guardou

E tu arrancas a haste frágil.

Na lapela com a mão delicada,

Colocas, com um sorriso vagaroso,

A flor, arruinada por ti.

E caminhas pela estrada poeirenta;

Em redor, todo o campo queimado,

Flui do céu um calor intenso,

E tua flor há muito murchou.

Ela crescia numa sombra serena,

Nutria-se da chuva matinal,

E era mortificada pela poeira ardente,

Queimada pelo raio do meio-dia.

E então? Compaixão vã! 


\section{Saber que fora ela criada}

Para ficar um instante

Nas imediações do teu coração (TURGUÊNIEV, 1978, 21).

O comentário a seguir, que possui um caráter extratextual, é facultativo à minha interpretação a seguir. No entanto, eu o citarei, visto que, extrapolando o conteúdo dessas miniaturas líricas do plano da alegoria poética para a biografia do autor, ele permite revelar e acentuar a tendência ideológica geral do poema. No comentário acadêmico acerca das obras completas de Turguêniev, afirma-se que "Flor" fora supostamente dedicado a Avdótia Ivánova, costureira assalariada que serviu na casa da mãe do poeta em Spásskoie-Lutovinov, com quem Turguêniev tivera uma relação e, em abril de 1842, uma filha ilegítima. Muito mais tarde, o escritor falou a respeito em carta ao marido de Viardot: "Eu era jovem [...] eu me sentia entediado no campo e prestei atenção em uma costureira bastante bonitinha, que minha mãe empregara, e sussurreilhe duas palavras - ela veio até mim, dei-lhe dinheiro, e depois parti, e isso é tudo" (TURGUÊNIEV, 1978, 21).

Não me aprofundarei mais nos detalhes biográficos. Esse aspecto atraiu-me exclusivamente como um determinado fundo vital, no qual talvez seja possível, de forma mais penetrante, perceber o "tema" poético do poema "Flor". Então, mais uma vez, já está no relato: uma flor "simples e modesta" "cresceu só" sob os ares de um "bosque sombrio". - O herói lírico arranca "a haste frágil" e, "com um sorriso vagaroso", coloca-a "na lapela" de sua sobrecasaca. - Em seguida, ele caminha "pela estrada poeirenta": "Ao redor, todo o campo queimado, flui do céu um calor intenso", e é natural que a flor, em sua lapela, que, até então, "crescia numa sombra serena", "nutria-se da chuva matinal", "era mortificada pela poeira ardente", tenha murchado "queimada pelo raio do meio-dia". Desse enredo batido, o autor retira o final "moral":

\section{E então? Lamento vão!}

\section{Saber que fora ela criada}

Para ficar um instante

Nas imediações do teu coração. 
Certamente que, se o discurso se referisse apenas a um "incidente botânico", não haveria nada de especial, porque nada de notável se passou. Mas o sentido poético desses versos líricos, naturalmente, é outro: a autodeterminação do autor na existência, a afirmação de relações de princípio - ideológicas, éticas e estéticas - do seu " $E u$ ” com o mundo, com o outro, enfim, com tudo o que, para ele, se define como "não $E u$ ". E é preciso dizer diretamente que, na declaração ostensiva de seu credo no quarteto final, o herói lírico do poema "Flor" apresenta um aspecto muito pouco atraente. Mas o principal - o principal! - é que em sua relação com o mundo ele se apresenta como um antípoda completo do Sonhador de Noites brancas, segundo minha caracterização anterior desse herói.

É necessário dizer algo acerca do herói lírico do poema "Flor". Ele é um egocêntrico coerente e por princípio do tipo stirneriano. A princípio, ele não apresenta nenhuma relação ética com o mundo. O mundo e tudo no mundo tem um sentido e foi criado apenas para a satisfação das necessidades do seu "Eu". Por isso, tudo pode ser sacrificado por esse "Eu" absolutizado. E sem qualquer hesitação moral, "com um sorriso vagaroso". Se o "lamento" pela vítima "arruinada" de repente, contra qualquer expectativa, for despertado na alma, filosoficamente é refutado como um sofrimento "vão". E assim por diante.

O amoralismo demonstrativo com que tudo que é declarado nos leva a lembrar de uma das confissões de Pietchórin, de Liérmontov:

Há, não obstante, um imenso prazer em nos apoderarmos de uma alma jovem que mal acaba de desabrochar! Ela é como uma flor que exala sua melhor fragrância ao contato com o primeiro raio do sol; devemos arrancá-la nesse instante e, depois de saciados com a sua fragrância, abandoná-la no meio do caminho: pode ser que alguém a apanhe. Sinto em mim essa avidez insaciável que devora tudo o que encontra no seu caminho; olho para os sofrimentos e alegrias dos demais somente naquilo que me diz respeito, como para um alimento que sustenta as minhas energias espirituais (LIÉRMONTOV, 1988, 101)

Em relação a esse fragmento antológico de $O$ herói do nosso tempo, o poema de Turguêniev não pode ser compreendido como uma paráfrase poética simplificada.

O sonhador de Noites brancas, repito, aprecia o "instante" de permanência "de 
uma alma jovem que mal acaba de desabrochar" "nas imediações" de seu coração e mostra-se infinitamente agradecido a ela por lhe ter permitido revelar ao máximo o potencial moral de sua alma. No contexto do Pietchórin turguenieviano, tudo mostra-se precisamente o oposto. No primeiro caso (em Liérmontov), o valor subjetivo do "instante" para o herói se encerra no "imenso" prazer voluptuoso estimulado por uma violação demoníaca da soberania espiritual de uma pessoa estranha (recordo o próprio comentário de Pietchórin: “[...] o meu primeiro prazer é subordinar à minha vontade tudo o que me rodeia; [...] Servir de motivo para os sofrimentos e alegrias de alguém sem ter para tanto qualquer direito real não será o sustento mais doce do nosso orgulho?", LIÉRMONTOV, 1988, 101) No segundo caso, em "Flor”, de Turguêniev, que é o que propriamente nos interessa, onde não há sequer o "prazer" de Pietchórin, determinado pelo doce triunfo do arbítrio amoral, mas há uma utilização rudimentar egoísta do outro com uma confiança inabalável em seu direito a isso, assim como ele, o outro também foi "criado para isso", - aqui, parece, o "instante" da posse geralmente não é sentido como um valor desprovido de qualquer exclusividade na existência do herói, já que é de uma série interminável de "instantes" semelhantes que se constitui sua vida. Por isso, não apenas o sentimento de "compaixão", mas também o sentimento de "gratidão" pelo "instante" que lhe foi concedido, diferentemente do Sonhador de Noites brancas, é plenamente estranho à alma do herói lírico do poema "Flor".

Então, como é possível explicar esse caso intrincado - o uso por parte de Dostoiévski, na qualidade de epígrafe, das linhas do poema de Turguêniev, que, no contexto do autor, possuem não apenas um sentido diferente, mas diametralmente oposto ao daquele que elas recebem na correspondência com o conteúdo da novela Noites brancas?

Primeiramente, o autor de Noites brancas, pode-se supor, tinha completa convicção de que a maioria esmagadora de seus leitores não se recordava de um poema de um certo T. L, que ninguém conhecia, perdido em um periódico de cinco anos atrás, e não poderiam realizar essa operação de reconstrução do contexto e de revelação do sentido autêntico das linhas analisadas que eu agora o faço. Para eles, esses leitores, a epígrafe possui apenas um único sentido, aquele que as linhas adquirem no "campo de forças" "do romance sentimental" de Dostoiévski. E essa epígrafe reinterpretada combinava de modo tão orgânico com o conteúdo de Noites brancas, "se encaixava" 
com tanto êxito na focagem da concepção artística da autor, que o escritor não pôde abster-se da utilização de suas possibilidades significativas.

Mas aos leitores que se lembraram do poema "Flor", que tiveram a oportunidade de relacionar a utilização de suas linhas finais em Noites brancas com o antigo sentido proposto por Turguêniev - e nisso, parece-me, está o principal "artifício" do pensamento secreto e profundamente oculto de Dostoiévski -, não poderia deixar de impressionar o nítido contraste entre a ênfase metaforicamente reinterpretada na epígrafe da novela, a benção de gratidão mútua de uma personagem por outra pela participação fraternal que surge em cada uma delas pelo destino da outra, e o individualismo romântico feroz do herói lírico de Turguêniev, que se expressa de modo concentrado nessas mesmas linhas. Para esses leitores (e de modo mais imediato, acredito, Dostoiévski contou com os "nossos" - os literatos conhecidos do antigo círculo de Bielínski -, os autores atuais de "O contemporâneo" de Nekrássov e Panáiev" ), a epígrafe de Noites brancas revelava-se como uma ruptura polêmica, em cujo interior cruzavam-se hostilmente posições éticas e ideológicas diametralmente opostas. E certamente essa foi uma polêmica com Turguêniev, principal adversário de Dostoiévski daqueles anos. Foi um "remoque" virulento em sua direção, já que no plano das relação poeticamente sublimes e dos "ideais calorosos" dos heróis de Noites brancas, o demonismo declarativo e, ainda por cima, de qualidade extremamente ruim do herói lírico do poema "Flor", de Turguêniev, revelava-se em toda a sua fealdade.

Seria plenamente possível colocar um ponto final aqui. No entanto, tenho de fazer observações adicionais acerca da controversa obra seguinte de Dostoiévski com o individualismo romântico, particularmente no que diz respeito à figura do príncipe Valkóvski, de Humilhados e ofendidos, que, de um lado, inteiramente no espírito stirneriano, repudiando a moral, o dever etc. como um "disparate", à pergunta de Ivan Petróvitch: "E o que não é um disparate?", responde com franqueza: "O que não é disparate... é a personalidade, sou eu próprio. Tudo, e todo o mundo foi criado para mim. [...] nunca estou disposto a sacrificar minhas conveniências, seja por quem for. [...] Remorsos não tive por nada...” (DOSTOIÉVSKI, 1972-1990, 365-366). Por outro lado, escarnece a torto e a direito de seu interlocutor, que, tal como o Sonhador de Noites Brancas, desempenha na relação de Aliócha e Natacha Ikhmiênieva, que ele

\footnotetext{
${ }^{5}$ Revista $O$ contemporâneo, da qual N. Nekrássov era o editor. (N. T.)
} 
ama, "um papel secundário", sendo "quase que um encarregado de recados deles" (palavras de Valkóvski). "É verdade que um de seus escritores chegou a dizer certa vez, se bem me lembro, que talvez o maior feito de um homem seja contentar-se na vida com um papel secundário... [...] mas o caso é que Aliócha the tirou a noiva" (DOSTOIÉVSKI, 1972-1990, 358) e etc. Nas declarações apresentadas pelo príncipe Valkóvski, encontramos a expressão das mesmas posições, cujo cruzamento polêmico foi demonstrado mais acima nas duas leituras opostas da epígrafe de Turguêniev em Noites brancas. Dessa forma, se Dostoiévski de fato recebeu o poema "Flor" de modo tão penetrante e refletiu sobre ele de modo tão polêmico, como procurei demonstrar em meu artigo, ele deve ser levado em consideração no estudo da gênese do tipo individualista romântico na obra do escritor, a começar pelo príncipe Valkóvski, de Humilhados e ofendidos. Mas isso já é assunto para um outro estudo. Adiemos para uma próxima oportunidade.

Tradução: Samuel Junqueira Antoniasse ${ }^{6}$

\section{Referências bibliográficas}

- CHÊNNIKOV, G. K. "Évoliutsia sentimentalnogo i romantitcheskogo kharakterov v tvortchestve ránnego Dostoiévskogo". In: Dostoiévski: Materiali i issledovania. Leningrad, 1983. T. 5, p. 90-100.

- ___ CHÊNNIKOVA, L. L. Istoria rússkoi litieraturi XIX vieka, 70-90-e godi. Moscou, 2005.

- DOSTOIÉVSKI, F. Noites brancas. Tradução de Nivaldo dos Santos. São Paulo: Editora 34, 2005.

"Unijiennie i oskorbliónnie". In: Polnoe sobrânie sotchiniénii v 30 t.

Sotchiniénii: V. 3 т. Leningrad: Naúka, 1972-1990.

- KIRPÓTIN, V. I. "Proizvediênia sorokovikh godov". In: Izbrannie raboti v trior tomakh, v. 3. T: Dostoiévski. Moscou: 1978.

- LIÉRMONTOV, M. I. O herói do nosso tempo. Tradução de Paulo Bezerra. Rio de

\footnotetext{
6 Bacharel em Letras (Português e Russo) pela Universidade de São Paulo (2012). Mestre pelo Programa de Pós-graduação em Literatura e Cultura Russa da mesma universidade. Contato: samjunqueira@gmail.com. (N. T.)
} 
Janeiro: Editora Guanabara S. A., 1988.

- MANN, I. V. “Sem' znakovikh slov: (O Biélikh Notchakh dostoievskogo)”. In: Turguêniev i drugie. Moscou, 2008.

- MOTCHÚlSKI, K. V. Gógol. Solovióv. Dostoiévski. Moscou, 1995.

- OTVERJENNI, N. Stirner i Dostoiévski. Moscou, 1925.

- TURGUÊNIEV, I. S. “Flor”. In: Anais da Pátria, 1843, nº 8, p. 296.

- __ Polnoe sobrânie sotchiniênii v 30 t. Sotchiniénia. Moscou, 1978. 